\title{
Revolução periférica dos dados em tempos de pandemia global
}

\author{
Rodrigo Firmino, ${ }^{a}\left[\right.$ () Debora Pio ${ }^{\mathrm{b}}(\mathbb{C})$ e Gilberto Vieira ${ }^{\mathrm{c}}$ \\ ${ }^{a}$ Pontifícia Universidade Católica do Paraná, Programa de Pós-Graduação em Gestão Urbana, Curitiba, \\ PR, Brasil. Email: rodrigo.firmino@pucpr.br
}

${ }^{\text {b }}$ Universidade Federal do Rio de Janeiro, Programa de Pós-Graduação em Comunicação e Cultura / Rede de ativismo Nossas, Meu Rio, Rio de Janeiro, RJ, Brasil. Email: deboradpio@gmail.com

c Pesquisador independente, data_labe, Rio de Janeiro, RJ, Brasil. Email: gilberto@datalabe.org

https://doi.org/10.47235/rmu.v8i1.156

"O ator proposto - pensado

literalmente de baixo para cima, corporificado e territorializado -, corresponde, potencialmente, ao circuito inferior reconhecido por Milton Santos, em O Espaço Dividido (1979), para a compreensão íntegra da economia urbana. Mas, este ator também corresponde às formas sociais sobreviventes das sucessivas modernizações e às formas mais modernas que tiveram, historicamente, a capacidade de interagir com práticas ancestrais, como aquelas produções e comércios em que a negociação predomina sobre a conquista e a destruição do outro. Existe, portanto, uma vida de relações, resistente e tenaz, que se opõe à abstração exigida pela operação sistêmica da concepção hegemônica de mercado."

(Ana Clara Torres Ribeiro, 2005, p.12468)

Em "Território Usado e Humanismo Concreto: o Mercado Socialmente Necessário", Ana Clara Torres Ribeiro (2005) exalta a centralidade do território na busca por novos horizontes de resistência. $\mathrm{Na}$ verdade, ao lado de Milton Santos, Ana Clara já nos alertava, pelo menos desde os anos 1980, para a importância de compreendermos a força do "território usado" como campo de construção de utopias sob a ideia de ação política. Em um país marcado pela injustiça e desigualdade social, não é novidade que o novo coronavírus aumente exponencialmente os desafios para famílias que vivem em territórios populares como favelas, aldeias indígenas, quilombos e assentamentos. Dados do município do Rio de Janeiro de maio de 2020 (conhecidamente subnotificados) indicam que o número de mortes por Covid-
19 nas favelas cariocas cresceu mais de 10 vezes em apenas um mês (Barreto, 2020). A "normalidade", nestes casos, já está pautada, há muito tempo, pela dificuldade de acesso a empregos formais, programas sociais, educação e assistência médica de qualidade, assim como condições mínimas de saneamento básico - incluindo abastecimento regular de água (Souza, 2020), esgoto e coleta apropriada de lixo. Estima-se que sejam 13,5 milhões de pessoas (Nery, 2019) sobrevivendo com até 145 reais mensais. No contexto da crise global de enfrentamento à pandemia, uma questão de saúde, no Brasil, pode fácil e rapidamente tornar-se uma tragédia sanitária e humanitária. E nesses casos, dados e tecnologias digitais compõem diferentes narrativas, indissociáveis dos territórios, e a partir de distintos arranjos sociotécnicos.

\section{O vírus e seus modos de existência nos dados}

Em situações de exceção, há uma tendência de maior receptividade a experimentações rápidas e acríticas com todos os tipos de inovações técnicas. A fé na ciência e na tecnologia aumentam, e todos tornam-se impacientes por respostas rápidas e soluções definitivas para a crise ou para criar amenidades que forneçam uma sensação temporária de normalidade. Nesse cenário de desespero, também surgem posições negacionistas e irresponsáveis no tratamento da crise: tratar a doença como uma "gripezinha" (Congresso em Foco, 2020), culpabilizar o governo chinês pela suposta fabricação do vírus como parte de um plano de dominação comunista global, elevar a hidroxicloroquina (Reuters, 2020) e o vermífugo Annita (Schelp, 2020) como drogas salvadoras, ou definir o "isolamento vertical" (Sanches, 2020) como estratégia econômica, para citar apenas alguns 
exemplos mais recentes. Surgem, então, ondas diárias de artigos distorcidos, áudios inventados, notícias manipuladas. A estratégia de disseminar desinformação através das mídias sociais é ferramenta poderosa desde os últimos pleitos pelo mundo. Já não é mais segredo que as eleições de 2018 no Brasil foram definidas pelos grupos no WhatsApp com altas doses de mentiras e manipulações criminosas. É trágico e curioso ver como uma estratégia de marketing desenhada para a disputa eleitoral ganhou sobrevida em uma nova roupagem, passando a ser empregada como ação sistemática de governo, com estrutura técnica e administrativa reforçada e gabinete no Palácio do Planalto (Rudnitzki et al., 2020). Não seria exagero dizer que o WhatsApp se tornou ferramenta de governo.

É importante considerar ainda os riscos iminentes de ocultação e invisibilização dos dados públicos sobre a contaminação e as mortes em consequência da Covid-19. Para além da provisão insuficiente de testes e da consequente subnotificação de casos, mudanças na metodologia de contagem, exclusão de dados, barreiras ao acesso, atraso na liberação das informações consolidadas, dentre outras atitudes do governo federal, evidencia-se a centralidade dos dados na vida prática dos cidadãos, principalmente os que vivem em periferias e comunidades vulnerabilizadas, mas também no centro de decisões políticas que expõem os projetos de poder em disputa.

Coleta e manipulação de dados são ações políticas, a partir das quais se determinam políticas públicas, prioridades de acesso, e a própria existência de populações nos territórios urbanos. A falta de dados consolidados sobre as favelas é um problema histórico, que reflete muito a maneira de fazer política nessas localidades. Afinal, sem dados consistentes sobre a população, número de domicílios, informações sobre saneamento ou até mesmo hábitos culturais locais, torna-se inviável a implementação de políticas públicas. Um exemplo é o censo do IBGE de 2010, que estimava que a favela da Rocinha, considerada a maior do Brasil, tinha 69.161 habitantes, enquanto as entidades locais garantem que este número representaria cerca de metade da quantidade real de habitantes (Tabak, 2011). Ou seja, para órgãos oficiais, responsáveis por grande parte das decisões importantes sobre a cidade, há milhares de pessoas "não contabilizadas", ou seja, invisíveis.

A pandemia escancarou essa faceta da invisibilização pelos dados. Aos coletivos e grupos de favelas, que foram os primeiros a se organizar para oferecer uma resposta rápida à pandemia, também coube a responsabilidade de levantar dados demográficos (inexistentes em meios oficiais) para conseguir fazer a distribuição de doações como cestas básicas, água e kits de higiene e limpeza. Os relatos dos integrantes desses coletivos de favela dão conta que muitos moradores que apareceram pedindo ajuda sequer tinham documentos ou eram cobertos por qualquer tipo de assistência, como o Bolsa Família por exemplo. Assim, além de conseguir recursos através de financiamentos coletivos ou pedidos de doação no comércio local, também foi necessário criar estratégias para cadastrar pessoas, torná-las visíveis e atender a demanda por alimentos.

Na Vila Kennedy, Rio de Janeiro, um dos coletivos que está à frente da arrecadação desenvolveu uma base de dados simples para organizar informações sobre as condições em que vivem os atendidos. A base tem noventa famílias cadastradas, e diversas informações relevantes: $80 \%$ delas são chefiadas por mulheres; apenas $40 \%$ têm acesso à internet em casa; e apenas uma minoria conseguiu acesso ao auxílio emergencial ${ }^{1}$. Em busca deste tipo informação em canais oficiais, como o Instituto Pereira Passos, nota-se que a Vila Kennedy sequer é considerada um bairro para a Prefeitura do Rio de Janeiro. Outro exemplo que ilustra a situação é que a Secretaria Municipal de Saúde contabilizou os casos de coronavírus do bairro junto com os de Bangu, tornando inviável a coleta de informações e medidas específicas para a Vila Kennedy, que tem aproximadamente 150 mil habitantes, segundo estimativa das lideranças locais. Botafogo, localizado na Zona Sul do Rio e com cerca de $82 \mathrm{mil}$ habitantes (segundo o IBGE) conta com monitoramento próprio para o bairro. É unânime entre quem está na linha de frente da pandemia que a subnotificação não é o único problema grave, mas também a invisibilidade de pessoas que sequer têm um endereço fixo ou CPF, não são atendidas por nenhum projeto social e não têm emprego formal (Souza, 2020). Ou seja, como habitual no que se refere à presença do estado e 
serviços públicos nesses territórios, cabe às redes de solidariedade organizar, não apenas a assistência como os próprios dados e informações sobre a população.

$\mathrm{O}$ que nos interessa destacar aqui, em contextos de crise, são as "brechas" abertas por sujeitos que vivem nesses territórios usados. Um certo uso intensificado das tecnologias, e mais recentemente de dados, pode representar também possíveis canais de inovação, informação de qualidade e solidariedade. Logo que a pandemia se tornou uma realidade no Brasil, muitos perguntaram "o que vai acontecer quando o vírus chegar às favelas?" Essas localidades, que historicamente são vistas pelo poder público sob a ótica da ausência, seguem sem receber investimentos que deem conta de suas especificidades no contexto da crise. Por isso, moradoras e moradores se organizam para, mais uma vez, criar suas próprias alternativas. As iniciativas vão desde grupos de informação no WhatsApp a campanhas de financiamento coletivo e distribuição de insumos. Vai ficando evidente que tecnologias como essas são apropriadas de formas distintas, em contextos e arranjos sociotécnicos com propósitos completamente diferentes.

\section{Táticas de resistência nas margens}

Muito antes da pandemia, vários grupos já se organizavam em torno de uma solidariedade em rede, com ações transversais, especialmente em territórios vulnerabilizados. Essas iniciativas estão ligadas a lutas históricas de um ativismo de sobrevivência e por uma necessidade de fazer valer - à força, e muitas vezes "hackeando" redes e sistemas de infraestrutura - o direito de todos à cidade. É assim, por exemplo, que muitas áreas periféricas e de favelas lutam, há décadas, para conquistar menos que o mínimo em condições sanitárias e de mobilidade.

Para compreender melhor o lugar e importância dessas ações, fazemos uso de uma diferenciação conceitual proposta por Michel de Certeau (1994), que a partir da observação atenta de práticas sociais estabelece uma distinção entre estratégias e táticas - formas de agir determinadas pela composição social de quem as opera. As estratégias, que segundo Certeau são operadas por sujeitos com altos capitais políticos, intelectuais e materiais, pressupõe um próprio, um lugar seguro e racional de querer e poder. Em detrimento de uma estratégia, grupos historicamente empobrecidos, violados e explorados estabelecem táticas - ações determinadas pela ausência de um próprio instituído; uma espécie de outro lugar que lhes permite mobilidade diante de imposições hegemônicas (categoricamente determinadas e construídas por estratégias). Isto é, essa lógica pode nos ajudar a entender como as táticas inventadas por moradores de favelas e periferias no contexto da pandemia do novo coronavírus (mas não apenas) representa o surgimento de um novo tipo de luta cuja centralidade são os usos de tecnologias digitais e dados. Um movimento narrativo contra hegemônico, da margem.

A necessidade de se "hackear" a cidade (e subverter a lógica do plano, transgredir o projeto) fica cada vez mais evidente, principalmente a partir das possibilidades de conexão, coleta e manipulação de dados, codificação/programação e produção autônoma de conteúdos, dadas pelas tecnologias da informação e comunicação desde o final do século XX. A figura do hacker cívico ganhou popularidade, mas parece haver uma diferenciação fundamental entre, ao menos, dois tipos de arranjos sociotécnicos ligados a essa realidade (Luque-Ayala et al., 2020). Há, por um lado, o digital como forma de ativismo, ou "intervenções movidas a dados", na figura clássica dos programadores e participantes de hackatons e da cultura maker. Por outro lado, há o que se pode conceber como o encontro do digital com formas pré-existentes de ativismo, ou "intervenções situadas". Ou seja, de um lado, desenvolvem-se aplicativos baseados em dados governamentais abertos para monitorar, por exemplo, os trajetos dos ônibus, e de outro, estabelecem-se lutas históricas por direitos e infraestruturas urbanas com o suporte de tecnologias digitais e o trabalho com dados. É nesta segunda possibilidade que parecem surgir algumas táticas de resistência pela margem, que se fazem mais evidentes em tempos de crise global generalizada. A disputa de narrativas pelos dados tornou-se terreno essencial da luta por direitos e visibilidade, e o caso de desaparecimento e manipulação dos dados da Covid-19 pelo governo federal em junho de 2020 (Azevedo, 2020), em uma tentativa de modificar a percepção da gravidade de sua 
inabilidade para lidar com a crise, escancara as assimetrias presentes nessa disputa.

Há inúmeros exemplos. A lista de transmissão "Coronanews" dispara diariamente no WhatsApp checagem de informações falsas que circulam pelos grupos de família. O grupo "Corona nas Periferias" é uma biblioteca de mídia que reúne serviços e notícias sobre a pandemia com foco nas periferias e favelas. O canal da "Agência Mural" distribui, todas as manhãs, um podcast curto com relatos de quem vive a quarentena nas "quebradas" de São Paulo. Além dos canais públicos, grupos de ativistas, jornalistas, profissionais da saúde, funcionários públicos, vizinhos e parentes se organizam para prestar apoio a quem está mais vulnerável. Desde o começo da quarentena, no mundo todo, o WhatsApp foi a mídia social que mais cresceu em tráfego de dados, com aumento de uso estimado em 40\% (Kantar, 2020).

Como já mencionamos, as táticas de financiamento coletivo multiplicaram-se rapidamente, quase todos com o mesmo apelo: arrecadar dinheiro para garantir cestas básicas, água, produtos de higiene e limpeza, auxílio transporte para trabalhadores, logística de entrega de materiais, compra de EPIs (Equipamentos de Proteção Individual), etc. O Meu Rio, organização que desenvolve tecnologias e mobilizações para aproximar os cidadãos da tomada de decisão política, fez o esforço de reunir oito coletivos de diferentes favelas da região metropolitana (Acari, Complexo do Alemão, Complexo da Maré, Duque de Caxias, Santa Cruz, Sepetiba, Vila Kennedy e Viradouro) para fazer uma vaquinha unificada. A organização arrecadou, até maio de 2020, mais de 200 mil reais para distribuir entre os coletivos, e decidiu que a campanha continuará enquanto a pandemia e o cenário de emergência permanecer. Neste período já foram atendidas mais de 1.500 famílias.

Política, tecnologia, dados, comunicação, assistência social e um forte lastro territorial/espacial dão o tom em todos esses movimentos. Nas periferias de grandes cidades, muitas organizações estão criando melhores maneiras e ferramentas para ajudarse mutuamente. $\mathrm{O}$ \#CoronaNaBaixada reúne cerca de 100 organizações na Baixada Fluminense, e suas ações se dividem em três frentes: (1) compartilhar experiências de solidariedade local; (2) disseminar estratégias para orientar os residentes a ficar em casa; (3) estabelecer contatos com os meios de comunicação e autoridades públicas, a fim de tornar visíveis os problemas enfrentados por esses territórios e monitorar as medidas que estão sendo adotadas.

\section{Dados territorializados}

Muitas iniciativas evidenciam uma preocupação com a visualização das informações e suas formas de espacialização. Na região metropolitana de Curitiba, o Mapa da Solidariedade (iniciativa de pesquisadores da UTFPR, do Centro de Formação Urbano Rural Irmã Araújo e Observatório das Metrópoles - Curitiba) organiza dados e informações georreferenciadas sobre vulnerabilidades e ações de resistência à crise do Covid-19 na periferia (Borges, 2020). O mapa é ferramenta essencial ao dar visibilidade a um grande número de iniciativas de pequeno porte e desconhecidas de boa parte da população, e ao desconstruir a narrativa de que a periferia é desorganizada e passiva no enfrentamento à pandemia.

Diante do apagão de dados que já mencionamos, o coletivo Voz das Comunidades no Rio de Janeiro criou a página Covid-19 nas Favelas, ${ }^{2}$ um dashboard atualizado diariamente com dados de contágio e morte pelo vírus em quinze favelas da cidade, frequentemente ignoradas nas narrativas oficiais dos grandes jornais e emissoras de TV. O interessante é que, além da Prefeitura e Secretarias de Estado, as fontes dos dados contemplam centros comunitários de saúde e ONGs locais. Pelos mesmos motivos, em São Paulo, a União de Núcleos, Associações de Moradores de Heliópolis e Região (UNAS), organizou um levantamento para mapear os casos de contaminação e morte no território da favela, para o qual não existem dados oficiais minimamente atualizados. $\mathrm{O}$ resultado é um relatório, ${ }^{3} \mathrm{em}$ constante atualização, com espacialização dos dados, capaz de fornecer informações importantes às várias ações da UNAS nesse território.

No Complexo de favelas da Maré, um bairro com 140 mil habitantes da Zona Norte da capital fluminense, o boletim "De olho no corona!" é ação central da Redes da Maré, organização histórica do território que mantém a campanha "A Maré diz não ao coronavírus". A campanha é viabilizada a partir de articulações com parcerias 
institucionais e pessoas físicas e possibilita, a partir do boletim, a existência de um canal com os moradores para acolher pautas sobre acesso a direitos, violações, casos de Covid19 e as condições das políticas públicas no território durante a pandemia. Segundo a terceira edição, ${ }^{4}$ lançada com dados até o dia 18 de maio, a diferença entre os dados oficiais e os dados do boletim era de $193 \%$ em número de casos e de $65 \%$ em número de óbitos. Ou seja, enquanto a prefeitura do Rio contabilizava 89 casos e 23 óbitos, o boletim contabilizava 261 casos e 38 óbitos no Complexo da Maré.

Ainda na Maré, o data_labe, ${ }^{5}$ uma organização de mídia, dados e educação formada por quinze jovens de diversos territórios e repertórios, vem desenvolvendo, desde antes da pandemia, o Cocôzap ${ }^{6}$ - um projeto de mapeamento, incidência e participação cidadã sobre saneamento básico em favelas. Através de denúncias dos moradores via WhatsApp o projeto mapeia violações de direitos sanitários, promove encontros comunitários e produz reportagens com base em dados públicos e histórias da comunidade. $\mathrm{O}$ data_labe pode ser entendido como um desses novos movimentos sociais, organizados pela juventude a partir de suas referências conceituais e estéticas que aproximam tecnologia e consciência de classe; empoderamento racial e políticas públicas; direitos humanos e empreendedorismo, horizontalidade e modelo de negócio. No contexto da pandemia, diante da impossibilidade das articulações corpo a corpo, o arranjo sociotécnico que sustenta o Cocôzap (e, indiretamente, os problemas de saneamento da Maré, assim como as próprias ações do data_labe) precisou ser reconsiderado. Desde a implementação das medidas de isolamento social no Rio, o grupo tem se articulado para produzir narrativas sobre a centralidade dos debates e dados envolvendo a precarização dos serviços sanitários nas favelas do país e as consequências disso para a saúde das populações mais vulneráveis. É uma tentativa, também, de se conectar às redes de solidariedade, informações e ações já existentes, e fortalecer laços que já existiam, como mencionamos anteriormente.

\section{Conclusão}

O data_labe surge, no escopo de todos esses exemplos e comparações, como uma plataforma urbana situada (intervenção situada) que desafia e transcende as epistemologias tradicionais e as orientações políticas associadas aos domínios dos grupos mais comumente associados a hackers cívicos (as intervenções movidas a dados, citadas anteriormente). Há uma conjunção de fatores presentes na essência desses casos, que representa um arranjo sociotécnico capaz de reunir diversas pautas temáticas relacionadas à gestão das cidades e ao território a partir do uso de dados, tecnologias digitais, ativismo de mobilização, conexões em rede com outras organizações, e construção de narrativas contra-hegemônicas, no sentido de se compreender e dar visibilidade aos temas e histórias dos corpos e territórios da margem.

O CocôZap é um caso paradigmático nesse sentido. Ao gerar dados a partir dos próprios moradores e organizar discussões sobre saneamento, desnaturalizando a falta ou baixa qualidade desses serviços e materializando seus componentes, atores, controvérsias, etc., o data_labe promove o que é conhecido nos estudos de ciência e tecnologia - em especial na Teoria AtorRede (Latour, 2012) — como abertura da caixa-preta dessa infraestrutura básica na Maré. Esse tipo de ação é fundamental para a disputa de posição e poder na política de saneamento, que está constantemente em construção e precisa ser desafiada a partir de outros diagnósticos e narrativas.

Os dados e as ações (políticas e de solidariedade), mediadas por algumas ferramentas, parecem estar formando uma nova frente de ativismo político nas favelas e periferias. Não estamos falando de um tipo de luta que sempre esteve presente nesses territórios de sobrevivência. Várias das táticas que levantamos aqui fazem parte do que temos entendido como "revolução periférica dos dados" que assume um papel importante no engajamento e na capacidade de incidência dos moradores de favelas e periferias nas políticas locais. A ideia central dos coletivos, organizações e projetos parece ser disputar a narrativa que se criou em torno dos dados: num extremo, vulnerabiliza os usuários das plataformas digitais, redes sociais e aplicativos de todo tipo; e noutro, credibiliza quem quer que apresente dados para comprovar falácias e mentiras na rede. É importante evidenciar que não se trata aqui de uma revolução em sua concepção clássica 
de ruptura e conflito, mas ao contrário, do jogo de conter e resistir (Hall, 2003), das táticas inventadas nos lapsos de tempo, nas brechas de sistemas instituídos e que oferecem as reinvenções tão fundamentais para a superação de desigualdades. Os dados e o digital parecem ser um componente diferencial importante no âmbito de novas formas para compreender e valorizar processos de luta por direitos invisibilizados e negligenciados por assimetrias de poder. Passa a ser importante considerar a própria gestão das cidades a partir das relações entre dados, narrativas, ativismo digital e infraestruturas urbanas.

Todas essas ações e possibilidades de articulação, mediadas ou não por tecnologias, parecem se alinhar a um dos cenários propostos por Rafael Evangelista (2020) no segundo texto da série Lavits_Covid-19, "a

\section{Notas \\ ${ }^{1}$ Informações constantes na base de dados/planilha da "Casa de Aya", o coletivo de moradores da Vila Kennedy. \\ ${ }^{2}$ Ver painel em: https://painel. vozdascomunidades.com.br.}

\section{Referências}

Azevedo, A. (2020) Governo adota estratégia da desinformação com dados da covid-19. Correio Braziliense, 7 de junho de 2020. Disponível em: https://bit.ly/3fMR9gj. [Consultado em: 19 de junho de 2020].

Barreto Filho, H. (2020) Covid: mortes avançam em favelas e superam $3^{a}$ cidade com mais óbitos no RJ. UOL Notícias, 10 de maio de 2020. Disponível em: https://bit.ly/2BzcoTW. [Consultado em: 19 de junho de 2020].

Borges, L. (2020) Fotografia da resistência: mapa virtual reúne iniciativas solidárias e comunidades vulneráveis de Curitiba. Terra de Direitos, 12 de maio de 2020. Disponível em: https://bit.ly/2Nnmav8. [Consultado em: 19 de junho de 2020].

Certeau, M. (1994) A invenção do cotidiano I: as artes do fazer. Petrópolis, Vozes.

Comunicação Casa (2020) Organizações e lideranças da Baixada Fluminense lançam manifesto cobrando medidas de prevenção distopia de aceleração está a caminho?", que se desenham em meio à emergência de reação à crise: o de ruptura. A pandemia global e inédita que estamos vivendo é resultado de catástrofes ambientais, políticas econômicas pré-anunciadas e que agora exigem rupturas. Certamente será uma disputa injusta diante dos contextos de exceção e aceleração apresentados por Evangelista. Elas podem vir desorganizadas diante das estruturas criadas pelos sistemas financeiros e pelas grandes corporações, mas é nas periferias que as rupturas se tornam concretas, no "território usado" e no "humanismo concreto" de Ana Clara Torres Ribeiro. Os exemplos que trouxemos aqui são parte de um movimento ainda desigual, mas fundamental para o entendimento de um futuro próximo cuja centralidade deveria ser a conquista de comunidades mais justas, sustentáveis e felizes.

\footnotetext{
${ }^{3}$ Ver relatório em: https://bit.ly/3hPHpnx.

${ }^{4}$ Ver relatório em: https://bit.ly/37ZazMw.

${ }^{5}$ Ver: http://datalabe.org.

${ }^{6}$ Ver site da plataforma em:

http://cocozap.datalabe.org.
}

ao Coronavírus. Casa Fluminense, $26 \mathrm{de}$ março de 2020. Disponível em: https://bit.ly/2Ym3odX. [Consultado em: 19 de junho de 2020].

Congresso em Foco (2020) "Gripezinha" $e$ "histeria": cinco vezes em que Bolsonaro minimizou o coronavírus. UOL Notícias, 1 de abril de 2020. Disponível em: https://bit.ly/2YZsTkh. [Consultado em: 19 de junho de 2020].

Evangelista, R. (2020) A distopia de aceleração está a caminho? Série Lavits_Covid-19, Lavits, 3 de abril de 2020. Disponível em: https://bit.ly/2Z2RqoC. [Consultado em: 19 de junho de 2020].

Faria, T. (2020) Bolsonaro está convencido de que coronavírus é um plano do governo chinês. UOL Notícias, 16 de março de 2020. Disponível em: https://bit.ly/2AOPAQp. [Consultado em: 19 de junho de 2020].

Hall, S. (2003) Da diáspora: identidades e mediações culturais. Org. Liv Sovik. Belo Horizonte, UFMG. 
Kantar (2020) COVID-19 Barometer:

Consumer attitudes, media habits and expectations. Kantar, 3 de abril de 2020. Disponível em: https://bit.ly/2YnB4Yy. [Consultado em: 19 de junho de 2020].

Latour, B. (2012) Reagregando o social: uma introdução à Teoria do Ator-Rede. Salvador, EDUFBA, 2012.

Luque-Ayala, A.; Fariniuk, T.; Firmino, R.; Vieira, G.; Marques, J. (2020, no prelo) Platforms in the making: Hacking the urban environment in Brazilian cities, Em: Hodson, M.; Kasmire, J.; McMeekin, A.; Stehlin, J.; e Ward, K. (eds.) Urban Platforms and the Future City. London, Routledge.

Nery, C. (2019) Extrema pobreza atinge 13,5 milhões de pessoas e chega ao maior nível em 7 anos. Agência IBGE Notícias, 6 de novembro de 2019. Disponível em: https://bit.ly/2BzOSGr. [Consultado em: 19 de junho de 2020].

Reuters (2020) Bolsonaro anuncia aumento de produção de cloroquina; uso contra coronavírus não é comprovado. UOL Notícias, 21 de março de 2020. Disponível em: https://bit.ly/2Cx9rUH. [Consultado em: 19 de junho de 2020].

Ribeiro, A. C. T. (2005) Território Usado e Humanismo Concreto: o Mercado Socialmente Necessário. Anais do X Encontro de Geógrafos da América Latina,
20 a 26 de março de 2005, São Paulo, Brasil. São Paulo, Universidade de São Paulo.

Rudnitzki, E.; Scofield, L.; Ribeiro, R.; Viana, N. (2020) Assim bolsonarismo espalha morte e desinformação. Outras Palavras, 22 de abril de 2020. Disponível em: https://bit.ly/2Nj789E. [Consultado em: 19 de junho de 2020].

Sanches, M. (2020) O que é o isolamento vertical que Bolsonaro quer e por que especialistas temem que cause mais mortes? BBC Brasil, 25 de março de 2020. Disponível em: https://bbc.in/2YnvS70. [Consultado em: 19 de junho de 2020].

Santos, M. (1979) O espaço dividido: os dois circuitos da economia urbana dos países subdesenvolvidos. São Paulo, Edusp.

Schelp, D. (2020) Saúde aprovou pesquisa com Annita, 'segredo' de Pontes contra covid-19. UOL Notícias, 16 de abril de 2020. Disponível em: https://bit.ly/2Nngrp8. [Consultado em: 19 de junho de 2020].

Souza, B. (2020) A favela pede água. UOL Notícias, 9 de maio de 2020. Disponível em: https://bit.ly/31choZP. [Consultado em: 19 de junho de 2020]

Tabak, B. (2011) Maior favela do país, Rocinha discorda de dados de população do IBGE. G1, 21 de dezembro de 2011. Disponível em: https://glo.bo/3doqd4Y. [Consultado em: 19 de junho de 2020]. 